\title{
Persistent Polyneuronal Innervation in Partially Denervated Rat Muscle after Reinnervation and Recovery from Prolonged Nerve Conduction Block
}

\author{
Jacqueline A. Barry and Richard R. Ribchester \\ Department of Physiology, University Medical School, Edinburgh, EH8 9AG Scotland, United Kingdom
}

The contribution of activity to the long-term stability of synaptic connections is a subject of ongoing debate. In the present study we examined the effects of recovery from chronic disuse on the pattern of reinnervation of partially denervated adult rat skeletal muscles, using tension measurements, intracellular recordings, and observations of vital staining with activity-dependent styryl dyes. Fourth deep lumbrical muscles were partially denervated by crushing the lateral plantar nerve (LPN) bilaterally. Denervated muscle fibers became innervated by sprouts from the sural nerve (SN); 17-23 d after LPN crush, conduction in the right sciatic nerve was blocked by connecting an osmotic minipump containing tetrodotoxin to a cuff placed around the nerve. Distal muscles remained continuously paralysed for 10-19 d. After 2 weeks of nerve block the tension produced by stimulating the regenerated LPN axons had reached about $70 \%$ of the total. Regenerating axons in contralateral muscles reinnervated only about $55 \%$ of the muscle fibers. The level of dual innervation by both regenerating and intact axons reached about $50 \%$ of the total muscle fibers after 2 weeks of paralysis, but only about $20 \%$ in contralateral controls. We then measured the rate and amount of decline in motor unit tension and polyneuronal innervation in reinnervated muscles during an eight week period of recovery from nerve block. Some LPN and $\mathrm{SN}$ connections regressed within 2-4 weeks, but about $35 \%$ of the muscle fibers still retained convergent inputs from LPN and SN motor axons 8 weeks after activity had resumed. This was about twice the level observed in contralateral reinnervated muscles. Vital staining with the styryl dyes FM1-43 and RH414 confirmed that many of the reinnervated motor end-plates were convergently supplied by both SN and LPN axons. Intracellular recordings showed that most of the dually innervated fibers in paralyzed muscles were supplied by suprathreshold inputs from both LPN and SN axons. The increased excitability of these muscle fibers was partly explained by their two-fold increased input resistance. Input resistance recovered to control levels within 4 weeks of resumption of activity, but

\footnotetext{
Received Mar. 29, 1995; revised May 24, 1995; accepted May 31, 1995.

'l'his work was supported by Project Grants S/P/2341 and S/P/2526 from Action Research/SPARKS. We thank Mrs. Kay Grant for expert technical assistance with histology and Dr. David J. Price for very helpful comments on the manuscript.

Correspondence should be addressed to Dr. R. R. Ribchester, Department of Physiology, University Medical School, Teviot Place, Edinburgh EH8 9AG, Scotland, United Kingdom.

Copyright $(\mathcal{C} 1995$ Society for Neuroscience $\quad 0270-6474 / 95 / 156327-13 \$ 05.00 / 0$
}

dually innervated fibers in previously blocked muscles still gave mostly suprathreshold responses to stimulation of both the LPN and the SN. We conclude that chronic nerve conduction block generates or sustains a local environment which allows some convergent synaptic inputs on reinnervated muscle fibers to become consolidated and strengthened, independent of subsequent neuromuscular activity.

[Key words: rat, motor unit, motor nerve terminal, neuromuscular junction, sprouting, regeneration, polyneuronal innervation, synapse elimination, vital staining, paralysis, activity, neurotrophism]

Experimental studies of mammalian skeletal muscle show that after partial denervation, axotomized motor terminals degenerate and intact axons and nerve terminals sprout to reinnervate vacated motor end-plates (Brown et al., 1981; Ribchester and Barry, 1994). When regenerating axons return, they reestablish contact with muscle fibers that may already be innervated by sprouts, resulting in polyneuronal innervation (Guth 1962; McArdle, 1975; Brown and Ironton, 1978; Thompson, 1978; Taxt, 1983; Ribchester and Taxt, 1984; Ribchester, 1988). The subsequent competitive elimination of supernumerary terminals resembles events seen in neonatal muscles during normal postnatal development (Redfern, 1970; Brown et al., 1976; Betz et al., 1979; Bixby, 1981). Here elimination proceeds by progressive removal of synaptic boutons, with accretion of boutons belonging to the axon collateral that remains (Balice-Gordon et al., 1993). Muscle paralysis, either during development or reinnervation, increases the proportion of polyneuronally innervated fibers, either by stimulating nerve growth (sprouting) and/or by inhibiting elimination of convergent synaptic inputs (Thompson et al., 1979; Duxson, 1982; Taxt, 1983; Ribchester, 1993). There is some debate, however, over the extent to which activity selects which terminal boutons will survive. For example, Ribchester and Taxt $(1983,1984)$ showed that selective paralysis of motor units during nerve regencration favors cxpansion of the active motor units at the expense of the inactive motor units. Ridge and Betz (1984) showed that selective stimulation of motor units in neonatal muscles also confers a competitive advantage on the stimulated axons. Intracellular recordings have revealed acute heterosynaptic depression of synaptic inputs in isolated neuromuscular preparations and cultured myocytes (Betz et al., 1989; Lo and Poo, 1991; Dan and Poo, 1992), and repeated imaging of end-plates in vivo has demonstrated elimination of synaptic boutons after small areas of receptors disappear (Rich and Lichtman, 1988), or are rendered ineffective by blocking them with 


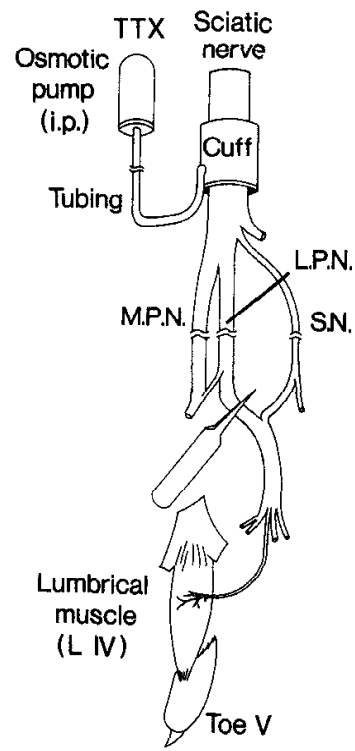

Figure 1. Diagram of the experimental design. In the first stage, fourth deep lumbrical muscles (4DL) were partially denervated by crushing the lateral plantar nerve (L.P.N.), which normally supplies 9-15 motor units to the muscle. After sprouting of intact sural nerve $(S . N$.$) axons$ and regeneration of LPN axons, nerve conduction in the entire motor nerve supply to $4 \mathrm{DL}$ was blocked for 1-3 weeks, by chronic superfusion of tetrodotoxin from an implanted osmotic minipump. Some animals were left for a further 2-8 weeks to recover from nerve block before isolated preparations of $4 \mathrm{DL}$ were made for analysis.

$\alpha$-bungarotoxin (Balice-Gordon and Lichtman, 1994). Other data suggest the effects of activity may be complex, however. Callaway et al. (1989) reported that twitch contractions of paralysed motor units in neonatal rabbit muscle were larger than their nonparalyzed competitors; and Nelson et al.(1993) showed that stimulation accelerated elimination of both stimulated and nonstimulated synapses on cultured muscle fibers. Finally some synapse elimination occurs in reinnervated adult muscle even when all the competing motor units are inactive (Ribchester, 1993).

In the present study we have further investigated the activity dependence of neuromuscular synaptic competition. Our aim was to determine whether increasing the initial extent of reinnervation and polyneuronal innervation of partially denervated muscles-by chronically paralyzing them-would subsequently lead to stabilisation or elimination of the additional inputs once activity resumed. The data show that within about 2 weeks of recovery from chronic nerve conduction block, some muscle fibers may lose either their sprouted or their regenerated inputs. But about half the polyneuronally innervated fibers retain convergent inputs, many of them generating suprathreshold synaptic responses. These fibers remained polyneuronally innervated in spite of the resumption of neuromuscular activity.

Some of the observations and data in the present report have been published in ahstract form (Barry and Ribchester, 1994a,b).

\section{Materials and Methods}

Partial denervation and paralysis of the fourth deep lumbrical muscle (4DL) was carried out on young adult female Wistar rats (initial weights greater than $120 \mathrm{gm}$ ). All surgical procedures were licensed by the UK Home Office and carried out under aseptic conditions and halothane anaesthesia $\left(5 \%\right.$ in $\left.\mathrm{N}_{2} \mathrm{O} / \mathrm{O}_{2} ; 1: 1\right)$. The animals had free access to water and feed at all other times.

The overall experimental design is diagrammed in Figure 1. The 4DL receives dual innervation (Betz et al., 1979) from the LPN (6-14 motor units, m.u.) and the $S N(0-6$ m.u. $)$. In normal adults, each muscle fiber is mononeuronally innervated, by either an LPN or an SN axon. When either the LPN or the SN is injured, the axons in the other nerve give rise to sprouts which collaterally innervate the denervated muscle fibers (Ribchester and Taxt, 1984; Ribchester, 1988, 1993). In the present series of experiments the LPN of both hind limbs was exposed close to the ankle and crushed for $30 \mathrm{sec}$ using fine forceps, thus effecting a major partial denervation of 4DL. The wounds were closed and sutured. In previous experiments (Ribchester, 1988, 1993) it was shown that partially denervated lumbrical muscles containing two or more motor units became comprehensively reinnervated by collateral sprouts by the time regenerating axons returned, that is about 14-20 d after LPN or SN crush. In the present experiments, the rats were reanaesthetized 17$23 \mathrm{~d}$ after LPN crush, and the right sciatic nerve was exposed in the thigh. An osmotic minipump (Alzet 2002) containing tetrodotoxin (TTX in citrate buffer, Calbiochem; $500 \mu \mathrm{g} / \mathrm{ml}$ in sterile saline, $200 \mu \mathrm{g} / \mathrm{ml}$ ampicillin) was implanted intraperitoneally as described previously (Betz et al., 1980; Taxt, 1983; Ribchester, 1993). In brief, narrow bore silicone rubber tubing (Dow Corning Silastic 602-105; i.d. $0.35 \mathrm{~mm}$, o.d. $0.64 \mathrm{~mm}$, mated with $602-135$; i.d. $0.51 \mathrm{~mm}$, o.d. $0.94 \mathrm{~mm}$ ) was led from the outlet of the minipump and cemented with silicone rubber to the inside of a $5 \mathrm{~mm}$ length of wider bore silicone rubber tubing (i.d. $2 \mathrm{~mm}$ ) which was placed around the sciatic nerve. The tubing, but not the cuff, was also filled with TTX. Internal and external wounds were sutured with $7 / 0$ and $6 / 0$ silk suture, respectively. Paralysis of the right hind limb was evident within $24 \mathrm{hr}$. The patency of nerve conduction block was monitored daily by observing the absence of toe-spreading reflexes on the blocked side when the animal was gently lifted by the tail, and the absence of withdrawal reflexes in response to firm pinches applied to the toepads with blunt forceps. Nerve conduction block was maintained for between 8-20 d (mean $13.5 \mathrm{~d}$ ).

Final experiments were carried out after about 2 weeks of nerve conduction block ( 0 Weeks Recovery) or after additional 2 , 4 , or 8 weeks of recovery from block (referred to as $2 \mathrm{wB} 0 \mathrm{R}, 2 \mathrm{wB} 2 \mathrm{R}, 2 \mathrm{wB}$ $4 R$, and $2 w B 8 R$, respectively, in the following text and figures). We did not monitor continuously the animals' use of their limbs once the block had worn off, but it was clear that the previously-paralyzed limbs were used normally as the animals moved around their cages; their toe spreading and withdrawal reflexes were completely restored. On the day of the final experiment, animals were terminally anesthetized (Sagatal, $110 \mathrm{mg} / \mathrm{kg}$ i.p.) and the sciatic nerve was exposed on the right side and cut proximal to the cuff. The nerve was electrically stimulated above and below the cuff using brief trains of supramaximal pulses $(0.1 \mathrm{msec}$, $10 \mathrm{~V} ; 70 \mathrm{~Hz}$ for $0.5 \mathrm{sec}$ every second). In the case of the $2 \mathrm{wB}$ 0R group (blocked up to the time of the acute experiment), no response was elicited from stimulation above the cuff, while stimulation below it evoked strong contractions in the lower limb. In the 2-8 week recovery groups responses were seen with stimulation both above and below the cuff. This test therefore confirmed the behavioral observations.

Nerve/muscle preparations of 4DL were made and placed in a Sylgard-lined chamber perfused with mammalian physiological saline (concentration, mM: $\mathrm{Na}^{+} 137.1, \mathrm{~K}^{+} 5 ; \mathrm{Cl}^{-} 150.8 ; \mathrm{H}_{2} \mathrm{PO}_{4}^{-} 0.3, \mathrm{Ca}^{2+} 8$, $\mathrm{Mg}^{2+} 2, \mathrm{HCO}_{3}-23.8$, D-glucose 11) bubbled with $95 \% \mathrm{O}_{2}, 5 \% \mathrm{CO}_{2}$. The relatively high $\mathrm{Ca}^{2+}$ concentration was used to improve the stability of intracellular recordings. The distal tendon, attached to the fifth toe, was pinned to the base of the chamber and the proximal tendon was attached by a short length of $6 / 0$ silk suture to a sensitive force transducer (SensoNor AE801). The muscle length was set for optimal tension production. The numbers of motor units were assessed by carefully grading the intensity of the nerve stimuli. Responses to tetanic stimulation (70 $\mathrm{Hz}$ for $1 \mathrm{sec}$ ) were also measured. Intracellular measurements were carried out either on cut-fiber preparations (Betz et al, 1979; Ribchester, 1988), or on muscles stretched to one-and-a-half to two times their resting length. Muscle contractions were almost eliminated with both methods: the cut-fiber muscle preparations became depolarized, inactivating voltage-dependent sodium channels; while stretched-fiber preparations expressed near normal resting potentials and action potentials but their myofilaments were pulled out of alignment, reducing contractile movements and force production. Suprathreshold and subthreshold synaptic responses were readily distinguished using this latter method. Focal recordings of endplate potentials (EPPs) were made from about 40 fibers, using standard intracellular recording techniques, with glass microelectrodes of ca. $40 \mathrm{M} \Omega$ resistance filled with $3 \mathrm{M} \mathrm{KCl}$. Tension and intracellular recordings were digitized using a modified SONY 
PCM 701ES digital pulse code modulator and recorded on VHS videotape. Measurements and analysis were carricd out either on-line or off-line, using a CED1401 + (Cambridge Electronic Design, Cambridge, UK) interface and a personal computer, using WCP software supplied by Dr. J. Dempster (University of Strathclyde, Glasgow). Estimates of muscle fiber input resistance were made in some preparations. In these experiments, whole muscles were pinned out slightly longer than their resting length. Superficial fibers were penetrated with 5-10 M $\Omega$ electrodes filled with $3 \mathrm{M} \mathrm{KCl}$. Hyperpolarizing current pulses of $30 \mathrm{msec}$ duration and up to $10 \mathrm{nA}$ in amplitude were passed through the recording electrodes and membrane potential was simultaneously monitored using the Wheatstone bridge circuit of our recording amplifier (WPI model M707). Input resistance was read from the bridge halance after subtracting the electrode resistance. Double microelectrode impalements of single muscle fibers with separate current- passing and recording microelectrodes would perhaps have provided more accurate measure ments, but this method is difficult to apply in lumbrical muscles without damaging muscle fibers, owing to their small diameter (ca. $10 \mu \mathrm{m}$ ) compared with most rat skeletal muscle fibers (Ribchester and Taxl, 1983; Betz et al., 1989). We therefore opted for the single microelectrode method, which enabled us to increase the number of muscle fibers sampled in each muscle.

Some muscles were stained with the vital aminostyryl dyes FM1-43 and RH414 (Molecular Probes, Eugene, Oregon). Preparations were bathed in a $2 \mu \mathrm{M}$ solution of FM1-43 and the sural nerve was stimulated at $30 \mathrm{~Hz}$ for $5 \mathrm{sec}$ every $15 \mathrm{sec}$, for $10 \mathrm{~min}$. The preparation was washed with physiological saline for $15 \mathrm{~min}$, then this was replaced with one containing a 15-20 $\mu \mathrm{M}$ solution of RH414. The LPN was stimulated using a similar pattern. After a further 30-60 min wash, preparations were viewed in a fluorescence microscope using a standard Nikon fluorescein excitation/emission filter block. Under these imaging conditions, synaptic boutons stained with FM1-43 (SN) fluoresced yellow/ green, while those stained with RH414 (LPN) fluoresced orange. Photographs were taken on high-speed Kodak Ektachrome film, scanned, enhanced on an Apple Macintosh Quadra using ADOBE PHOTOSHOP software, and printed on a Kodak ColorEase printer. Some preparations were destained using nerve stimulation. Low-light images (1-10\% transmission neutral density filter between the $100 \mathrm{~W}$ xenon light source and the preparation) were taken using a Falcon LTC1160 SIT (Custom Cameras, Wells, UK) and linear contrast stretched between equal limits using NIH IMAGE or IONVISION (Improvision, Coventry, UK) software.

Ir order to study the effects of paralysis under conditions of intense competition between sprouted and regenerated motor units, we restricted our analysis to muscles with two or more SN motor units. Data from muscles with single SN units were excluded because these muscles probably contained many fibers which were not innervated by sprouts, leaving regenerating axons free to reinnervate them without competition (Ribchester, 1988). All experimental groups comprised 7-12 animals. Data are given as mean + SEM unless stated otherwise. Statistical differences between groups were tested using one-way analysis of variance (ANOVA) with post hoc applications of Tukey's multiple range test unless otherwise indicated.

\section{Results}

Wc uscd a combination of isometric tension, intracellular recording and vital staining with activity-dependent styryl dyes to determine the state of motor units and the pattern of reinnervation after various periods of recovery from chronic nerve conduction block. We first present evidence that recovery from nerve block restored the contractile properties of the muscles. Next, we show from tension and intracellular data that paralysis enhances reinnervation, and produces long-lasting increases in levels of polyneuronal innervation in the partially denervated $4 \mathrm{DL}$ muscles. Finally, we report our attempts to explain differences in the strengths of synaptic inputs to polyneuronally innervated muscles in previously-paralyzed and control reinnervated muscles.

\section{Changes in muscle contractile properties with recovery from nerve block}

As expected from previous work (Ribchester and Taxt, 1983; Kowalchuk and McComas, 1987), a number of contractile prop- erties changed as a result of 2 weeks muscle disuse. Paralyzed muscles produced only about half the maximum tetanic force of contralateral reinnervated muscles. The tetanus:twitch ratio was about two-thirds the normal value, affecting LPN and SN units about equally (Figs. 2, 3). Twitch tension was unaffected by chronic paralysis, as in previous studies (Ribchester and Taxt, 1983; Ribchester, 1993). A noteworthy point is that the maximum isometric tension of both blocked and contralateral reinnervated muscles remained below that of unoperated control muscles over the entire experimental period. When compared with reinnervated contralateral controls, however, there was almost complete recovery of total tetanic tension and tetanus: twitch ratio within 2-4 weeks of nerve block wearing off (Fig. 3). Twitch contraction time also recovered as normal activity resumed (data not shown).

\section{Effect of paralysis and recovery on LPN and SN motor innervation}

As expected, crush injury of LPN axons triggered sprouting of SN motor axons, then regression as regenerating LPN axons returned (Ribchester, 1988). The extent of SN sprouting and LPN reinnervation varied considerably between muscles. Figure 4 summarises the results we obtained from eighty-eight muscles in which complete tension and intracellular data were obtained. (In a further 13 muscles, we obtained tension but not intracellular data. These muscles were included in the calculation of mean data shown in subsequent figures). The data in Figure 4 are ranked in each group according to the size of their tetanic tension responses to stimulation of the LPN. Each stacked bar shows the fractional contribution of LPN motor units (or fibers; open bars), SN motor units (or fibers; hatched bars), and the degree of overlap indicative of functional, or synaptic dual innervation (solid bars).

Inspection of the individual data in Figure 4 suggests that paralysis increased the fraction of the total muscle fibers reinnervated by regenerating LPN axons compared with reinnervated controls. Nine out of 10 muscles in the $2 \mathrm{wB} 0 \mathrm{R}$ group produced more than $50 \%$ of total tension upon tetanic LPN stimulation, and the LPN response was more $70 \%$ of total in 4 of these muscles. After 8 weeks recovery (2wB8R), 7 of 8 muscles still gave more the $50 \%$ of total tension on LPN stimulation, but only 2 of these muscles gave more than $70 \%$. By comparison, in muscles contralateral to group $2 \mathrm{wB} 0 \mathrm{R}$, tetanic stimulation of the LPN produced more than $50 \%$ of total tension in only 3 out of 9 muscles. Eight weeks later, the LPN contribution had scarcely increased beyond this: only 4 of 8 muscles showed LPN responses contributing more than $50 \%$ of total muscle tension. In unoperated muscles, LPN motor units contribute about $80 \%$ of total tetanic tension and the SN contributed about $20 \%$ (Fig. 3). Thus, paralysis accelerated the recovery of muscle fibers by regenerating axons, and it appeared that some, though not all, of the additional inputs were subsequently consolidated.

The differences in the extent of reinnervation comparing blocked and control muscles at any stage were not due to differences in the numbers of competing LPN and SN units. Figure 5 shows that the amount of LPN reinnervation was related to the number of intact, competing SN motor units, but the correlation was quite weak-especially in the case of the paralyzed muscles-and there were no significant differences comparing numbers of intact SN units between groups.

Means of the data from Figure 4 (together with tension data from other muscles in which no intracellular recordings were 


\section{A}

\section{Blocked}

\section{OwR}

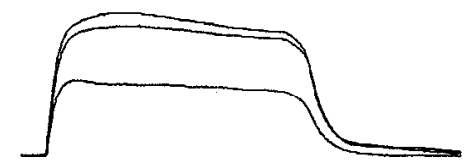

C

\section{4wR}

$B$

Contralateral

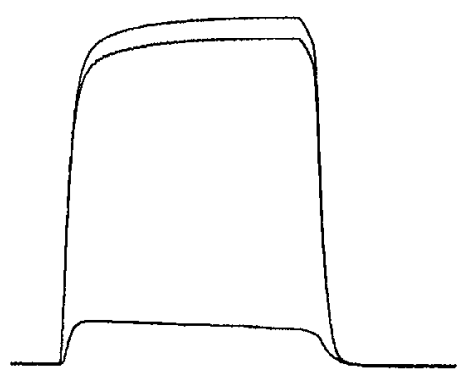

D
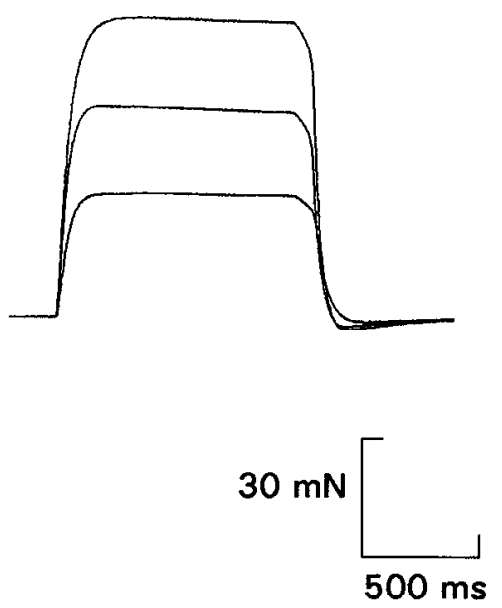

Figure 2. Examples of tetanic tension recordings from reinnervated 4DL muscles. A, After 2 weeks of sciatic nerve block (zero weeks recovery). Lowest trace SN (2 units), middle trace LPN (11 units), top trace combined stimulation; $B$, a contralateral reinnervated muscle. Lowest trace LPN ( 8 units), middle trace SN ( 5 units), top trace combined stimulation; $C, 4$ weeks recovery from nerve block. Trace order as in $A, 3$ SN units, 11 LPN units; $D$, contralateral muscle after the same recovery period. Trace order as in $B, 2$ SN units, 8 LPN units. The blocked muscle $(A)$ shows a relatively low tetanic tension, a marked sag in the tetanic tension response, and a pronounced posttetanic after-contraction on LPN or combined stimulation. These are all characteristics of chronically paralyzed reinnervated muscles. They recovered within $2-4$ weeks of resumption of neuromuscular activity.

made) are shown in Figure 6. The data have been lumped, ig noring the differences in the numbers of SN and LPN units between muscles. They show none the less, that in block + recovery muscles the mean extent of LPN reinnervation was consistently above that of the contralateral controls. The mean LPN tension perhaps declined slightly in previously blocked muscles with time, whereas in contralateral reinnervated muscles it increased slightly. Mean SN tension and numbers of fibers innervated declined with time in both contralateral and blocked muscles, but there were no systematic or statistically significant differences comparing these groups at different times. Thus, we may surmise that the overall effect of paralysis and recovery from nerve block was predominantly on the extent of reinnervation by regenerating LPN axons. Quantitatively, since the SN contributed about 3 motor units on average and the LPN contributed about 9 units, the fractional loss of connections from the intact $\mathrm{SN}$ axons was about $3 \%$ per motor unit, compared with less than $1 \%$ of connections per motor unit from regenerating LPN axons.

\section{Polyneuronal innervation}

Three main points can be made with respect to the dual innervation of muscle fibers by LPN and SN axons (Fig. 4). First, the levels were consistently higher in the blocked than in the corresponding control groups. Second, the level of dual innervation declined most in animals recovering from nerve block 
$\boldsymbol{A}$

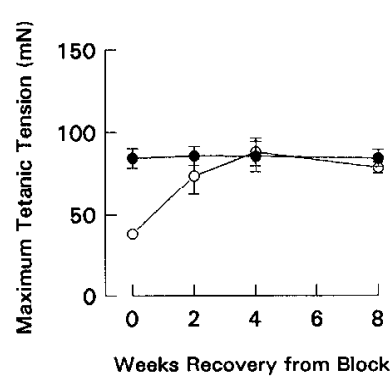

c

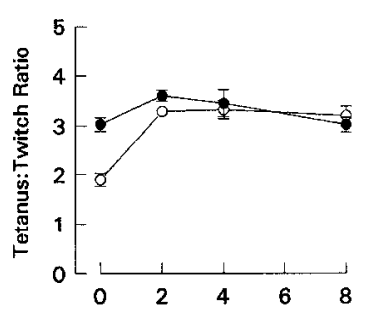

Weeks Recovery from Block
$B$

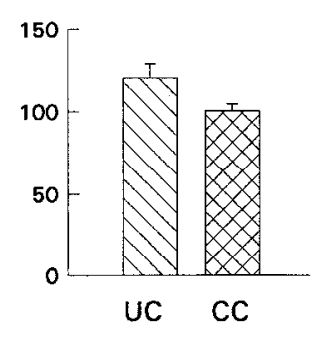

D

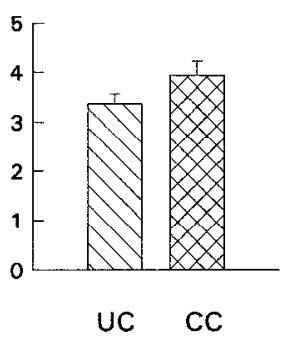

Figure 3. Tension data from reinnervated 4DL muscles after recovery from nerve block. A, Maximum tetanic force; open circles, blocked muscles; solid circles, contralateral reinnervated muscles. Eight to 10 muscles in each case. $B$, comparable data from unoperated controls $(U C)$ and nerve-crush only controls $(C C)$, which did not receive TTX. Eight muscles in each case. $C$, Tetanus:twitch ratio, same symbols as $A$. $D$, Comparable data from unoperated and crush controls. Both maximum tetanic tension and tetanus:twitch ratio recovered with 2 weeks of muscle activity resuming, but the tetanic tension did not recover to those of unoperated muscles within the 8 week recovery period studied.

(i.e., more in previously blocked muscles than in controls). Third, there were some clear discrepancies hetween the amounts of polyneuronal innervation estimated by tension overlap measurements, compared with intracellular recording. The discrepancies appeared to be due to differences in the numbers of subthreshold and suprathreshold synaptic inputs (analyzed further in a section below).

An overview of the changes in dual innervation is shown in Figure 7. Interestingly, three of the unoperated muscles showed evidence of a low level of polyneuronal innervation (cf. Taxt, 1983). The tension data show that in blocked muscles ( $2 \mathrm{WBOR}$ ), about $50 \%$ of fibers appeared to be dually innervated. With recovery, the level of dual innervation in previously blocked muscles appeared to decline steeply, to about $20 \%$ of fibers. In the contralateral reinnervated groups, tension overlap never exceeded $20 \%$ of the muscle and by 8 wceks only $5 \%$ of fibers were estimated to be dually innervated according to this method. Intracellular recordings showed consistently higher incidences of dual innervation than tension measurements in most of the groups. In the $2 \mathrm{wB} 0 \mathrm{R}$ group (paralysed up to the time of the acute experiments), about $50 \%$ of fibers gave synaptic responses to LPN and SN stimulation, a similar fraction to that inferred from the tension overlap. But by 8 weeks of recovery, intracellular recordings suggested that about $35 \%$ of fibers in previously blocked muscles were dually innervated, compared with about $15 \%$ in controls: that is, about 1.5 times and 3 times more, respectively, than the estimates based on tension overlap.

Overall, it appeared that the tension produced by SN and LPN motor units, and the levels of dual innervation of fibers by intact and regenerating axons had stabilized by eight weeks recovery from nerve block. We therefore did not examine any muscles after recovery periods greater than 8 weeks.

The physiological evidence of significant persistence of dual innervation was supported by observations of LPN and SN terminals stained with the vital aminostyryl dyes RH414 and FM143 (Betz et al., 1992; Ribchester et al., 1994). Figure 8A-F shows examples of mononeuronally innervated and polyneuronally innervated muscles examined during the recovery period. These examples show variable numbers of orange fluorescent (LPN) and yellow/green fluorescent (SN) boutons at single motor endplates in the reinnervated muscles. The variability in the numbers of boutons supplied by either nerve presumably reflects the variable synaptic strengths of the LPN and SN inputs in these fibers, (see below; cf. Harris and Ribchester, 1979; Betz et al., 1993). Sets of similarly colored boutons were selectively destained by stimulating the relevant nerve. Figure $7 G-L$ shows successive SIT camera (monochrome) images of a dually innervated terminal after loading with FM1-43 and RH414, during continuous stimulation of the LPN at $30 \mathrm{~Hz}$. Only the few boutons supplied by the LPN (visible as orange fluorescence down the microscope) destained, confirming that the pattern of staining was due to polyneuronal innervation of muscle fibers and not random staining of boutons by the differently colored dyes.

These observations confirmed the presence of persistent polyneuronal innervation in reinnervated muscles and further demonstrated that the convergent inputs were located and interdigitated at a single motor end-plate, rather than being separately or ectopically positioned.

\section{Tension-intracellular discrepancies in estimates of polyneuronal innervation}

We investigated the origin of the discrepancy between estimates of dual innervation based on tension versus intracellular measurements hy making intracellular recordings from intact preparations, mechanically stretched to the point where action potentials in the fibers no longer triggered production of significant muscle force or movement. We found we were able to make quite stable intracellular recordings of action potentials and EPPs from such preparations, even during tetanic stimulation of either of the nerves. Our working hypothesis was that the differences were due to some of the synaptic inputs to dually innervated fibers providing only subthreshold responses.

Examples of mononeuronally and dually innervated fibers are shown in Figure 9. We found numerous examples of dually innervated fibers giving subthreshold synaptic responses to one nerve, and a suprathreshold (action potential) response to stimulation of the other; while several other fibers gave suprathreshold responses on separate stimulation of both nerves.

Figure 10 shows the pattern of innervation of reinnervated muscles, in terms of the percentages of mononeuronally versus polyneuronally innervated fibers, in the form of nerve dominance histograms (compare for example with Ribchester and Taxt, 1983). In the present study, Groups 1 and 5 represent fibers innervated exclusively by the LPN and SN respectively; Group 3 represents fibers which gave action potentials in response to stimulation of both the LPN and the SN, while Group 2 fibers generated action potentials in response to I.PN stimulation and a subthreshold EPP to SN stimulation. For Group 4 fibers the reverse was true.

About $45 \%$ of fibers gave suprathreshold responses to both 


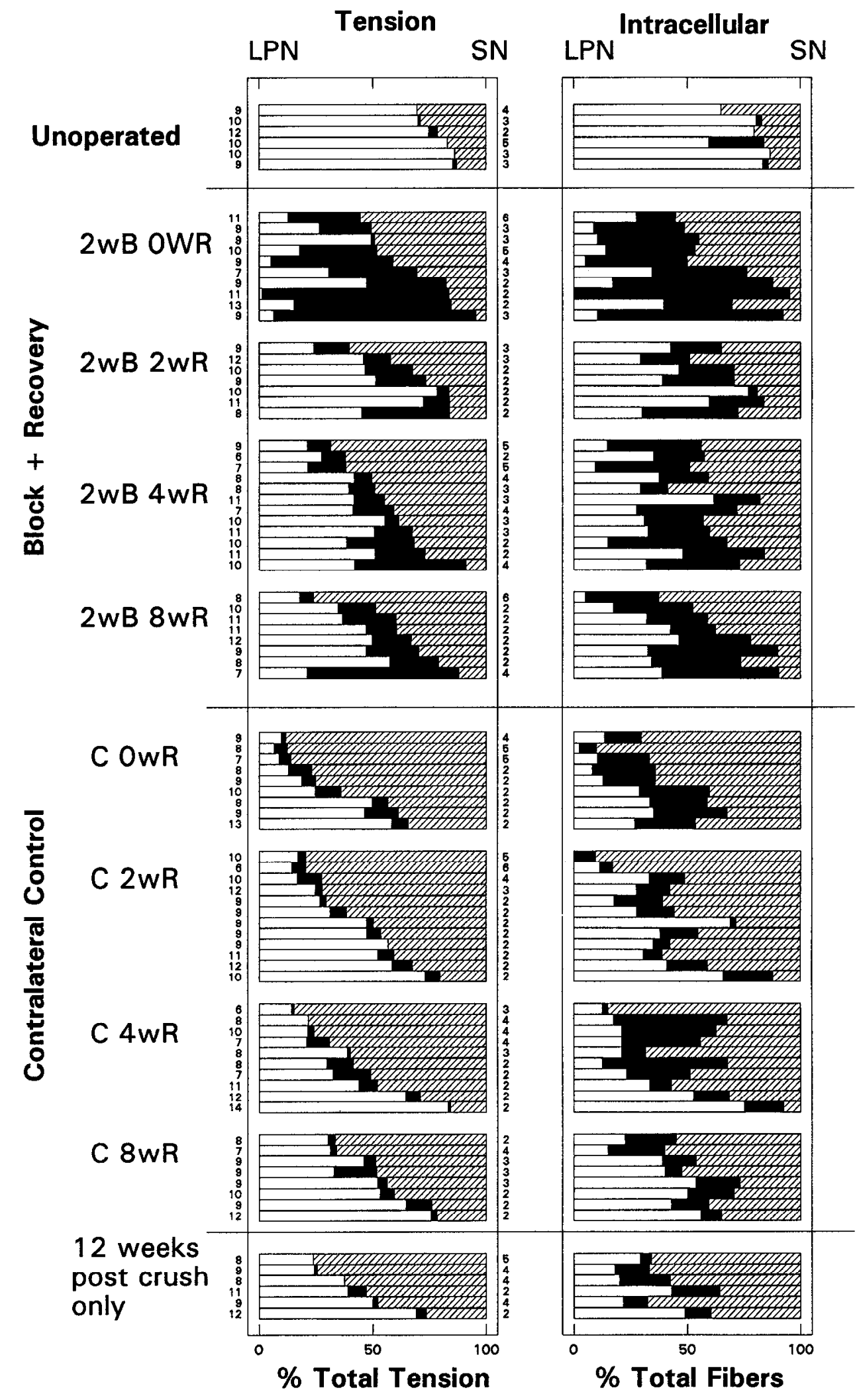

Figure 4. Overview of tension and intracellular data. Results from eightyeight muscles in which each pair of horizontal bars (left, tension; right, intracellular) represents the measurements obtained from one muscle. The data from each muscle are expressed as a percentage of the total indirect tension and the total number of innervated fibers respectively. In each case, the open bar shows the proportion of the muscle supplied only by LPN axons, the hatched bar shows the percentage supplied only by $\mathrm{SN}$ axons, and the solid bar shows the fraction of dually innervated fibers. The tetanic tension response to LPN stimulation (open+ fill) has been used as a key to rank the muscles in each group. The numbers down the left side of the tension data refer to the numbers of LPN units in each muscle, and the numbers down the right side are the numbers of SN units. Abbreviations at the left of the figure refer to the blocked, recovery, and control groups as designated in the Materials and Methods and Results sections.

LPN and SN stimulation in blocked muscles whereas only $15 \%$ of fibers responded in this way in contralateral muscles (Fig. 10 ). By 4 weeks of recovery, $27 \%$ of fibers still gave suprathreshold responses to both nerves, while only $9 \%$ of fibers did so in contralateral controls. Over the same period the fraction of total fibers that was polyneuronally innervated declined (see Fig. 7) suggesting that, as in development, elimination of terminals involved a gradual decrease in the efficacy of individual synaptic inputs (cf. Jones and Ridge, 1987; Balice-Gordon et al., 1993). 


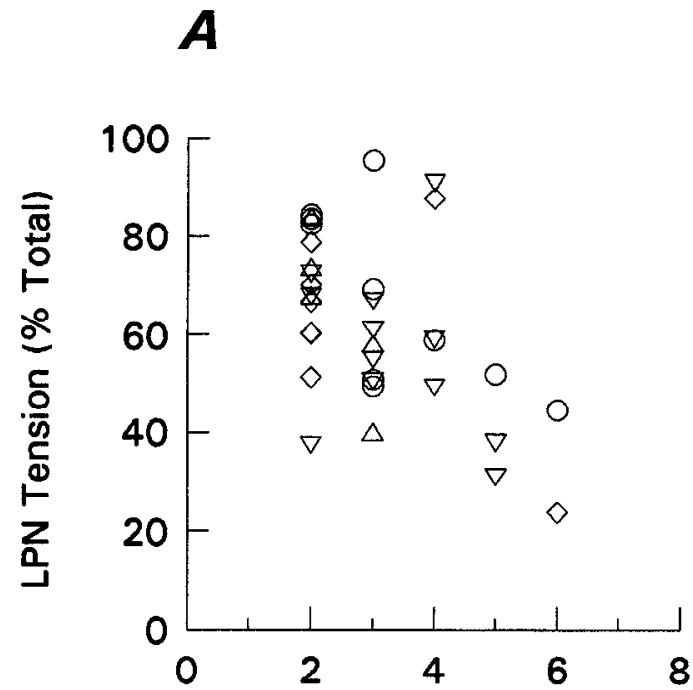

Number of SN units
$\boldsymbol{B}$

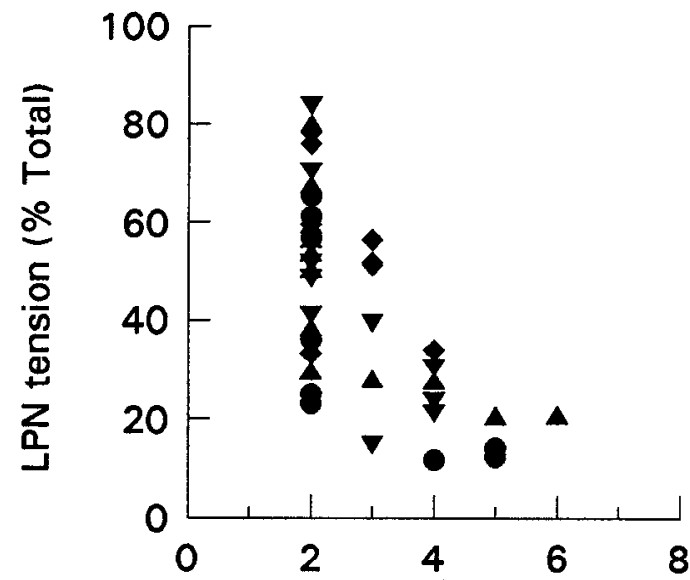

Number of SN units

Figure 5. Relationship between numbers of SN motor units and recovery of LPN motor unit tensions. The size of the maximum LPN tetanic tension responses are plotted against the number of sprouted, SN motor units in $A$, Blocked (+recovery) muscles; $B$, contralateral controls. Although there is clear evidence that the success of regenerating axons is limited by the number of remaining, intact axons-especially in controls-there were no systematic differences in the mean numbers of units in the blocked, recovery, or control groups (compare with Fig. 4). Circles, 2wB0R; upward triangles, $2 \mathrm{wB} 2 \mathrm{R}$; downward triangles, 2wB4R; diamonds, 2wB8R.

The relatively low incidence of subthreshold inputs in 2 week blocked muscles (no recovery) was reflected in the smaller discrepancy between tension and intracellular estimates of polyneuronal innervation compared with contralateral controls. For

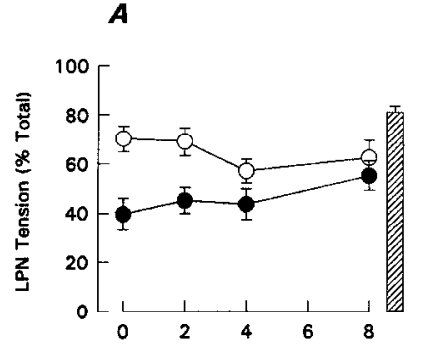

Weeks Recovery from Block

C

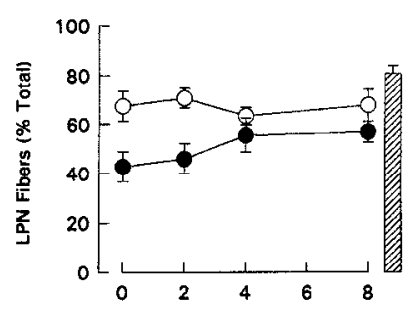

Weaks Recovery from Block

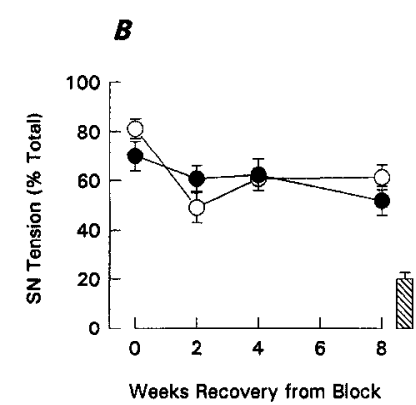

D

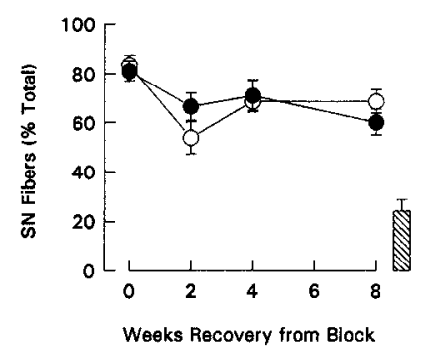

Figure 6. Recovery of LPN motor units. Mean and SEM of LPN and SN tension $(A, B)$ and intracellular $(C, D)$ recordings. The intracellular data are based on those presented in Figure 4 . The tension data include muscles shown in Figure 4, combined with those from other muscles in which only tension recordings were obtained. The hatched bars show the mean and SEs from unoperated muscles for comparison. Open circles are from blocked muscles, solid circles from contralateral controls. Differences between blocked and control muscles in $A$ and $C$ were statistically significant at 0 and 2 weeks recovery. instance, the tension overlap data from the muscles shown in Figure 10 suggested that $61.1 \%$ of the fibers were dually innervaled by suprathreshold inputs, and $62 \%$ of fibers observed in the intracellular recordings were dually innervated, although about one-fourth of these actually showed subthreshold responses from one of the nerves. By comparison, the incidence of subthreshold inputs in the contralateral controls at this time almost accounts for the observed discrepancy. Thus, $7.8 \%$ of fibers were dually innervated according to the tension measurements, while the intracellular recordings showed a dual innervation of $25 \%$ of fibers: $15 \%$ with both inputs suprathreshold and $10 \%$ with one input subthreshold. By 4 weeks recovery, the discrepancy in previously blocked muscle was similarly matched by the number of subthreshold inputs: $17 \%$ dually innervated according to tension measurements but $43 \%$ dually innervated according to intracellular recordings: $29 \%$ with both inputs suprathreshold. In contralateral muscles at this stage, the incidence of suprathreshold dual inputs was $9 \%$ of fibers, compared with $6 \%$ estimated from tension overlap. Overall, there was a good correlation between the numbers of dually innervated muscle fibers giving suprathreshold responses to the LPN and the SN (Group 3) and the tetanic tension overlap from the same muscles (Fig. 10B).

We investigated whether the discrepancies could be accounted for by differences in the input resistances of the muscle fibers in blocked and contralateral muscles. One of the earliest re sponses to disuse or denervation is a rise in muscle fiber input resistance due to a fall in membrane chloride permeability (Berg and Hall, 1975; Heathcote, 1989). Atrophy of the paralyzed muscle fibers would also be expected to increase their input resistances. We therefore surmised that the input resistance might be higher in blocked muscle fibers, which would increase the tendency of weak synaptic currents to generate suprathreshold synaptic responses. Stronger synaptic currents would be required to trigger action potentials in contralateral muscle fibers, to compensate for their lower input resistance. 
$\boldsymbol{A}$

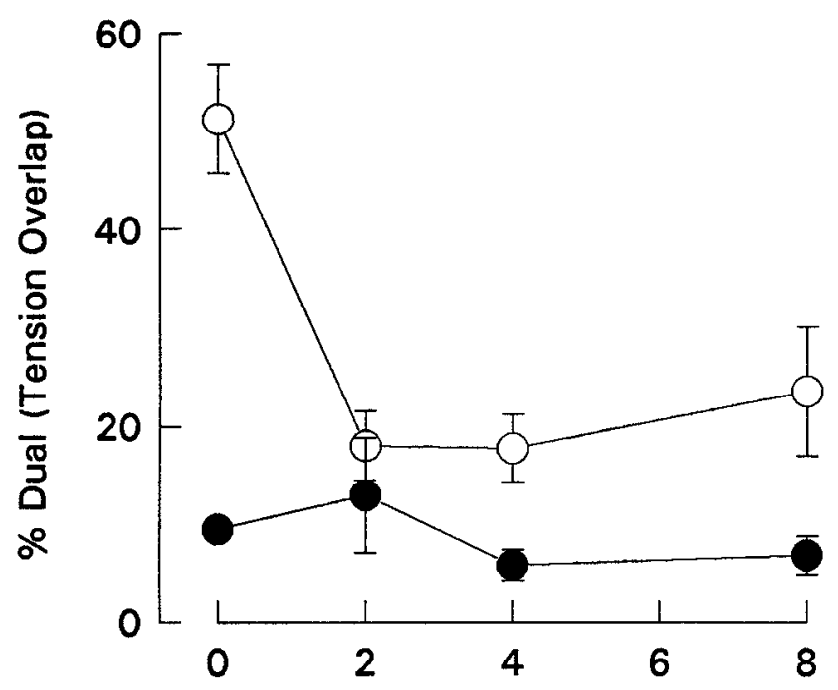

Weeks Recovery from Block
$\boldsymbol{B}$

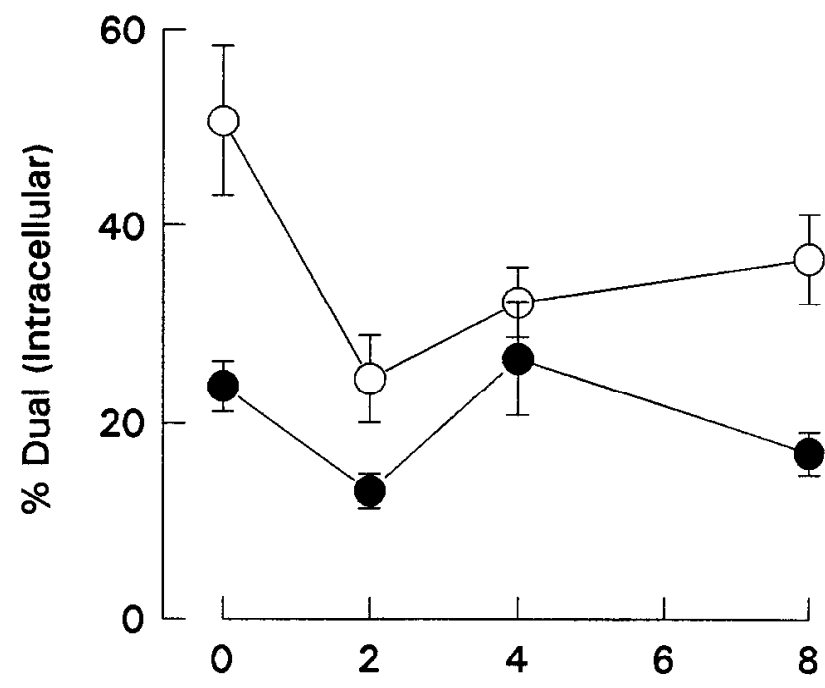

Weeks Recovery from Block

Figure 7. Dual innervation of muscle fibers. Mean and SEM of the percentage dual innervation, based on tetanic tension overlap $(A)$ and intracellular recording $(B)$. Open circles are from blocked muscles, solid circles from contralateral controls. Differences between blocked and control muscles at 0 and 8 weeks recovery were statistically significant.

The data shown in Figure 11 suggest that input resistance was about twice as high in the blocked muscles compared with the other groups. Thus a fall in muscle fiber input resistance on resumption of activity provides a partial explanation for the emergence of a tension-intracellular discrepancy in estimates of polyneuronal innervation. After 4 weeks recovery from block, however, there were no longer any systematic differences in muscle fiber input resistances on the blocked and control sides. Yet there were still significantly more suprathreshold inputs in previously blocked muscles compared with the contralateral muscles (Fig. 10).

\section{Discussion}

The results of the present study have implications for understanding how the number and disposition of motor neuron connections are regulated by neuromuscular activity. Our most important finding is that paralysis produced an enduring, stable pattern of polyneuronal innervation of about one-third of the lumbrical muscle fibers after partial denervation and reinnervation.

Persistent polyneuronal innervation has been described before, for example in reinnervated frog muscle (Werle and Herrera, 1991), or after treatment of neonatal rats with testosterone (Jordan et al., 1990; Lubischer et al., 1992). In mammalian muscles, persistent polyneuronal innervation is normally associated with separate motor end-plate sites, situated more than $1 \mathrm{~mm}$ apart (Kuffler et al., 1977). However, Brown et al. (1982) showed that focal polyneuronal innervation of mouse tensor fasciae latae muscle fibers persisted for more than $120 \mathrm{~d}$ after nconatal injection of botulinum toxin, although it was almost completely eliminated in gluteus muscles treated the same way. The present study shows that motor terminals derived from different axons in reinnervated adult rat lumbrical muscles are also able to coexist at an end-plate, with interdigitation of their synaptic boutons at sites of synaptic contact. Furthermore, the present study shows that increased levels of persistent convergent innervation appeared in reinnervated muscle as a consequence of earlier muscle paralysis, and remained even after physiological signs (contractile properties, input resistance) indicated that muscle activity had resumed. It is unlikely that the persistent polyneuronal innervation was due to ongoing injury from the implanted cuff around the sciatic nerve, because the numbers of motor units and their contractile properties were restored to normal within two weeks of the block wearing off. In any case this could not explain the (lower) levels of persistent dual innervation in the reinnervated controls that were not blocked. It is possible that persistent polyneuronal innervation is a peculiar feature of reinnervated muscle after partial denervation, although there are no systematic differences in the properties of LPN and SN motor units (Betz et al., 1979).

Previous studies have suggested that the rate of and outcome of synaptic competition are strongly dependent on the level of neuromuscular activity (O'Brien et al., 1978; Thompson et al., 1979; Thompson, 1983; Ribchester and Taxt, 1983; Ridge and Betz, 1984; Balice-Gordon and Lichtman, 1994; Purves, 1994). For example, Ribchester and Taxt (1983) showed that active axons have an advantage during competitive reinnervation of motor end-plates; and Balice-Gordon and Lichtman (1994) recently extended these findings to differences in the postsynaptic effectiveness of individual synaptic boutons at single motor endplates. However, Ribchester (1993) demonstrated that some neuromuscular synapse elimination can occur following nerve regeneration even when propagated activity in all the convergent inputs was blocked; and Balice-Gordon and Lichtman (1994) showed that very few terminals show loss of synaptic boutons when receptors covering more than $40 \%$ of the end-plate area are blocked with $\alpha$-bungarotoxin. Others have also shown that elimination of neuromuscular connections sometimes appears to 

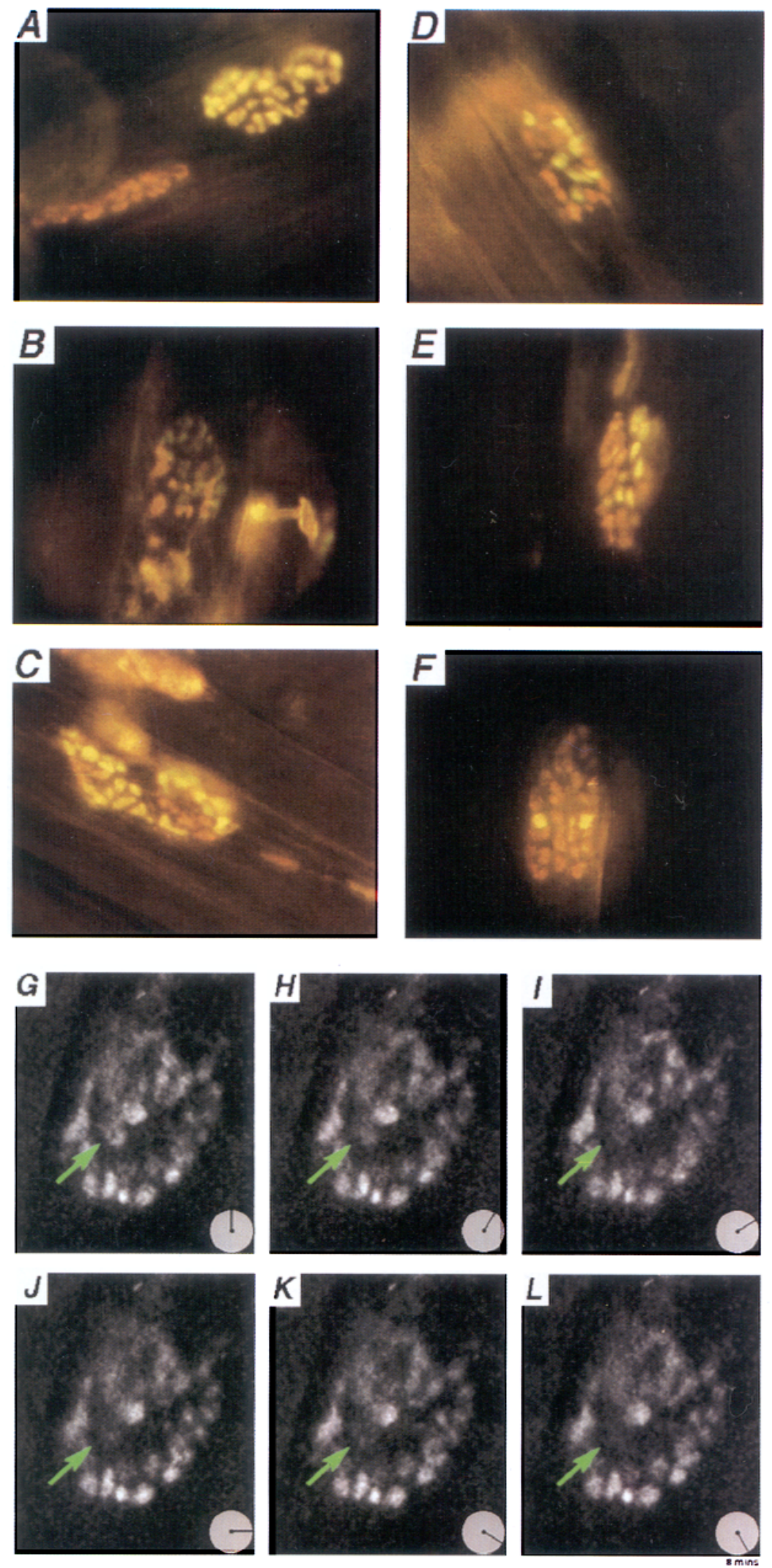

Figure 8. Motor nerve terminals stained with styryl dyes. The images were obtained 2-8 weeks after recovery from nerve conduction block. The $\mathrm{SN}$ motor terminals are stained with FM1-43 (yellow/green) and the LPN terminals are stained with $\mathrm{RH} 414$ (orange). $A$, Two end-plates on adjacent fibers, one innervated exclusively by LPN boutons, the other by $\mathrm{SN}$ boutons; $B-F$, dually innervated endplates with variable numbers of SN/LPN boutons. $G-L$, Successive SIT camera images of a dually innervated endplate during stimulation of the LPN at $30 \mathrm{~Hz}$ over an 8 min period. Most of the boutons were supplied by the SN and only a few - one of which is indicated by the green arrow-were supplied by the LPN. The LPN boutons destained during LPN stimulation. The other (SN) boutons did not destain significantly during LPN stimulation. Scale bar: $A-$ $F, 50 \mu \mathrm{m} ; G-L, 20 \mu \mathrm{m}$. 


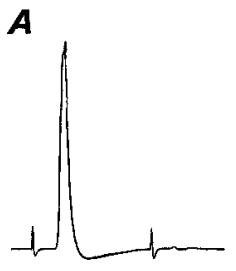

D

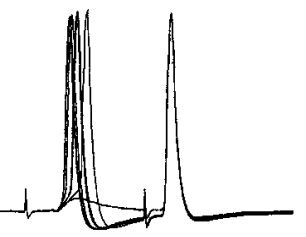

$\boldsymbol{B}$

$E$
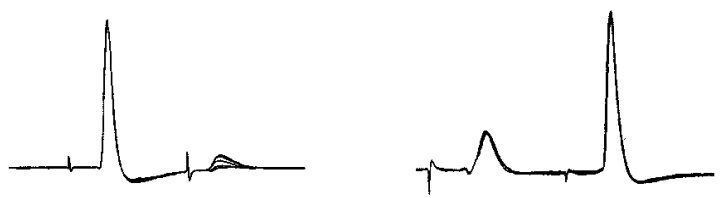

C

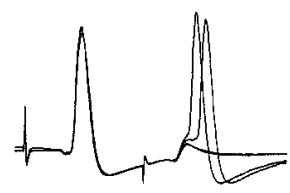

$\boldsymbol{F}$
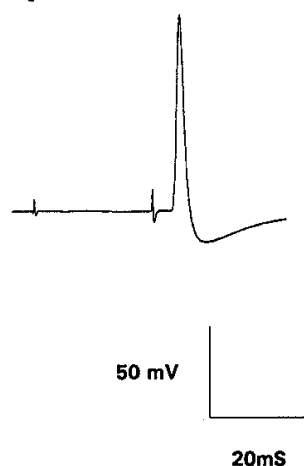

Figure 9. Intracellular recordings from stretch-fiber preparations. In each record, two to eight oscilloscope sweeps are superimposed and on each the LPN was stimulated first and the SN a few milliseconds later. $A$, Group 1 fiber, suprathreshold response from the LPN only; $B$, Group 2 fiber, suprathreshold LPN response, subthreshold SN response; $C$ and $D$, Group 3 fibers, with intermittent subthreshold responses from one of the two inputs and consistent suprathreshold responses from the other; $E$, Group 4 fiber, suprathreshold SN input and sub-threshold LPN input; $F$, Group 5 fiber, suprathreshold SN response only.

be "non-Hebbian": that is, independent of coincidence in the activity of pre- and postsynaptic cells (Callaway et al., 1989; Nelson et al., 1993). The present data complement and extend these findings. Thus, while our previous studies have shown that some synapses may be eliminated even when all the muscle fibers are paralyzcd (Ribchester, 1993), the present data suggest conversely that some fibers retain polyneuronal innervation several weeks after resumption activity in these fibers. The main implication from the present and previous data is therefore that differences in activity may be influential in determining the outcome of competition between synaptic boutons at an endplate, but they are not decisive at the level of individual muscle fibers, motur end-plates or terminal boutons.

As expected, paralysis increased the number of fibers dually innervated by sprouted and regenerating axons (Ribchester, 1993). Our data suggest that muscle paralysis during the critical period when regenerating axons begin to vie for synaptic space with sprouts from intact axons, provides an environment in which both sprouted and regenerated terminals are almost equally likely to become consolidated. Thus, after 8 weeks recovery from nerve block, many more of the dually innervated fibers showed suprathreshold responses to stimulation of both intact and regenerated axons, compared with contralateral muscles that were reinnervated but not blocked. The differences were partly explained by increased excitability of atrophic muscle fibers in the blocked muscles, on account of their higher input resistance. However, this explanation could not account for the strength or efficacy of convergent synaptic inputs in previously blocked Inuscles once activity had resumed. By 4 weeks (and possibly earlier) there was no difference in the input resistance of previously paralyzed muscle fibers compared with controls, yet twice as many of the dually innervated fibers gave suprathreshold responses to stimulation of the convergent inputs.

Thus, about $50 \%$ of the dually innervated end-plates resisted the forces of synaptic competition. Stimulation of both regenerated and sprouted inputs evoked suprathreshold synaptic responses in about half the fibers that remain polyneuronally innervated after paralysis and 4-8 weeks recovery (Fig. 10). A similar fraction of polyneuronally innervated fibers retained suprathreshold inputs in reinnervated controls, suggesting that the amount of consolidation of dual inputs may depend on the initial level of polyneuronal innervation, rather than any peculiar or pathological characteristic of previously paralyzed muscle fibers. We presume that some property of the motor end-plates encouraged both intact and regenerated synaptic boutons to remain in effective synaptic communication with individual muscle fibers. This property could be related to the organisation of cell adhesion molecules or ACh receptors (Covault and Sanes, 1986; Balice-Gordon and Lichtman, 1994); or to the production, action or consumption of a retrograde signal such as a neurotrophic factor (Funakoshi et al., 1993; Lohof et al. 1993), or a low molecular weight intercellular signaling molecule (Harish and Poo, 1992; Connor and Smith, 1994; Lindgren and Laird, 1994; Wang et al., 1995); or to respecification of surface molecules which may determine which subtypes of motor neurons are best matched to the muscle fibers they innervate (Gates and Ridge, 1992; Ribchester and Barry, 1994). A further possibility is that the consolidation of synaptic inputs is a function of the organisation of terminal neuroglia (Son and Thompson, 1995a,b). We also did not examine in the present study whether stronger neuromuscular transmission at polyneuronally innervated endplates in the previously blocked muscles was due to a higher and/or more equal quantal content of synaptic currents in the convergent inputs; or to a greater density of ACh receptors or Na channels; nor whether the physiological properties of the junctions correlated with structural features, such as the area of synaptic contact, the numbers of synaptic boutons, or the extent of junctional folds (Slater et al., 1992; Wilkinson et al., 1992; Lupa et al., 1995; Martin, 1995). The ease with which convergent terminals may now be identified by selective staining with aminostyryl dyes (Fig. 8) may allow us to design experiments to distinguish between the various possibilities.

Our results may have implications for the therapeutic potential of controlling activity in relation to neuromuscular function. Axons regenerating into partially denervated muscle rarely recover innervation of most of the fibers they previously innervated, because of the intensity of the competition from intact, sprouted axons (Thompson, 1978; Ribchester, 1988; present study). Our data show that it is possible to produce long-lasting improve- 
$\boldsymbol{A}$

\section{Blocked}

2wB OR

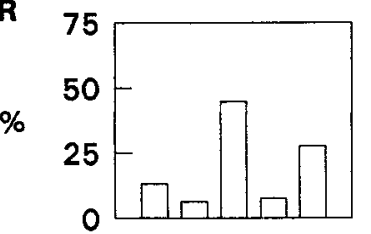

2wB 4R

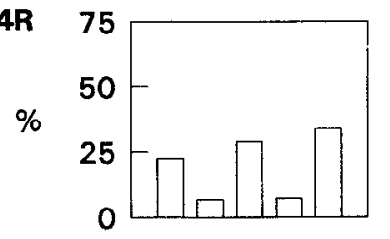

2wB 8R

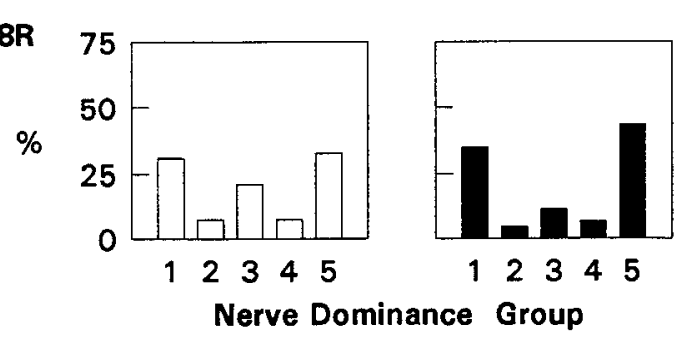

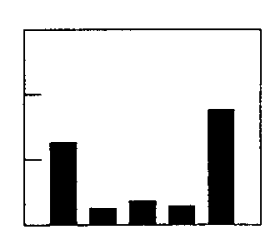

$\boldsymbol{B}$

\section{Contralateral}

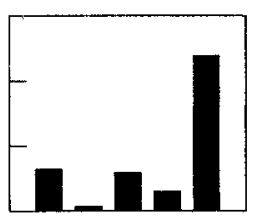

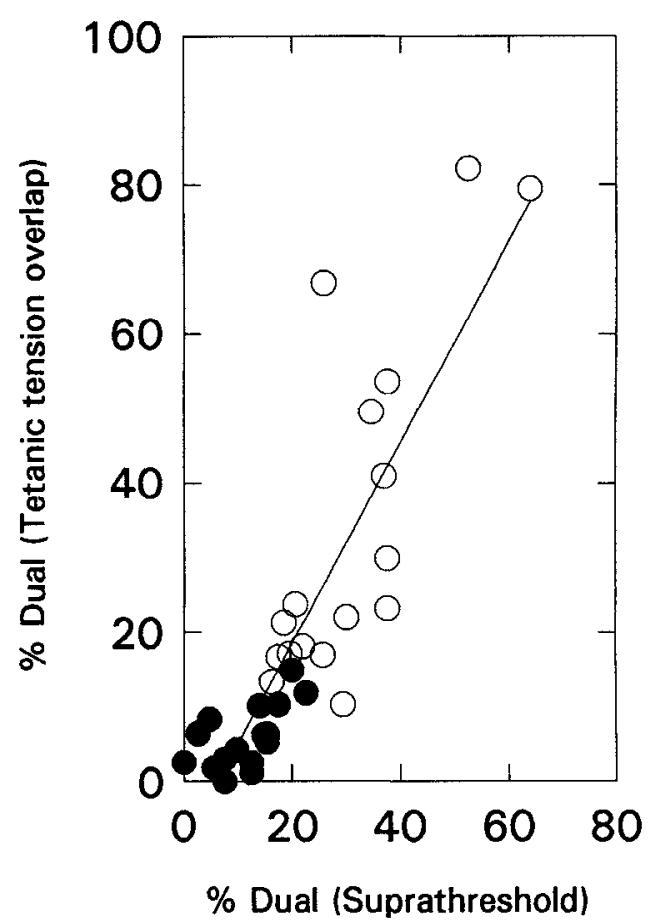

Figure 10. Data from stretch-fiber preparations. A, The bar charts on the left of the figure are nerve dominance histograms constructed from muscles 0,4 , and 8 weeks after recovery from nerve block. Each histogram shows the summed results from four to eight preparations. Each bar shows the percentage of the total fibers falling into the given dominance groups (see Fig. 9 and Results). B, Graph showing the correlation between estimates of dual innervation based on tension overlap, and the numbers of fibers in dominance Group 3 - that is, those which gave suprathreshold responses to stimulation of both the LPN and the SN. Open circles, previously blocked muscles; solid circles, contralateral reinnervated muscles. The regression line is the best fit to the combined data from blocked and contralateral reinnervated muscles.

ments in the extent of reinnervation of such muscles, simply by prolonging the period of muscle disuse. Deliberately paralysis is already used therapeutically in a clinical context. For example, there are a number of reports of the successful use of botulinum

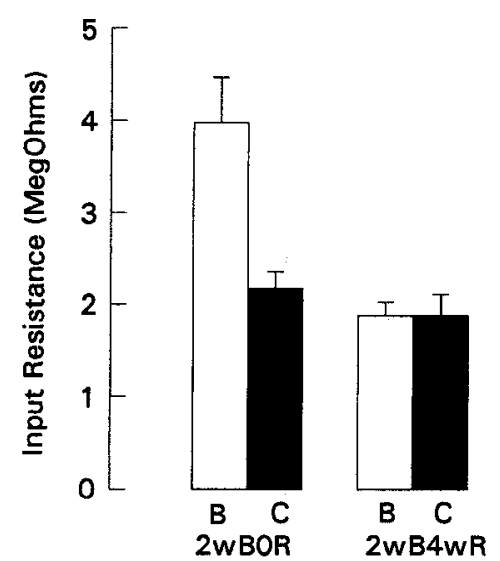

Figure 11. Input resistances before and after recovery from nerve block. The data were obtained from recordings made from intact preparations, 0 and 4 weeks after recovery from nerve conduction block. The input resistance of 2 week blocked muscles was significantly higher than in the other groups $(P<0.02$; Welch's test). From left to right, the numbers of muscles were: $5,6,7,5$. About 20 fibers were sampled in each muscle. Bars are the SEMs. toxin-induced paralysis in the treatment of palsies (e.g., Hesse et al., 1994). Conversely, electrical stimulation-which reduces muscle atrophy (Morkusch et al., 1990)—is reported to have no effect on nerve regeneration (Gutmann and Gutmann, 1944; Hines et al., 1945), or to increase the tension of reinnervated motor units (Nix and Hopf, 1983). However, electrical stimulation inhibits motor nerve terminal sprouting (Brown and Holland, 1979) and during development, it accelerates synapse elimination (O'Brien et al., 1978; Thompson, 1983). The effects of imposing activity electrically, or preventing atrophy chemically, are partly to suppress the expression of regulatory genes, such as myoD and myogenin (Dutton et al., 1993; Maltin et al., 1993; Merlie et al., 1994). The effects of inhibiting expression of these regulatory genes on the competitive elimination of neuromuscular synapses are not yet known. It would be interesting to investigate whether there is a trade-off between mitigation of sprouting and competitive synapse elimination, that could be exploited by controlling muscle activity or regulatory gene expression exogenously.

Finally, our data suggest that reinnervated adult skeletal muscles may offer a paradigm for the study of physiological interactions between closely spaced convergent synaptic inputs, like those found on the dendrites of neurones elsewhere in the nervous system. The small size and the large number and complexity of dendritic branches and the synaptic inputs neurons in the CNS receive, hampers their direct investigation using a com- 
bination of morphological and physiological techniques. The study of persisent focal innervation of motor end-plates by ditferent axons may provide an accessible route to the elucidation of any common cellular mechanisms controlling convergence and divergence in the nervous system.

\section{References}

Balice-Gordon R, Lichtman J (1994) Long-term synapse loss induced by focal blockade of postsynaptic receptors. Nature 372:519-524

Barry JA, Ribchester RR (1994a) Effects of recovery from chronic nerve-conduction block on elimination of polyneuronal innervation in partially denervated and reinnervated rat muscle. J Physiol (Lond) 476:62-63.

Balice-Gordon R, Chua CK, Nelson CA, Lichtman JW (1993) Gradual loss of synaptic cartels precedes axon withdrawal at developing neuromuscular junctions. Neuron 11:801-815.

Barry JA, Ribchester RR (1994b) Visualization of synaptic vesicle recycling at polyneuronally innervated neuromuscular junctions in isolated adult rat lumbrical muscle. J Physiol (Lond) 481:39.

Berg DK, Hall ZW (1975) Increased extrajunctional acetylcholine sensitivity produced by chroic post synaptic neuromuscular blockade. J Physiol (Lond) 244:659-676.

Betz WJ, Caldwell JH, Ribchester RR (1979) The size of motor units during post-natal development of rat lumbrical muscle. J Physiol (Lond) 297:463-478

Betz WJ, Caldwell JH, Ribchester RR (1980) Sprouting of active nerve terminals in partially inactive muscles of the rat. J Physiol (Lond) 303:265-279.

Betz WJ, Chua M, Ridge RMAP (1989) Inhibitory interactions between motoneurone terminals in neonatal rat lumbrical muscle. J Physiol (Lond) 417:25-51.

Betz WJ, Mao F, Bewick G (1992) Activity-dependent staining and destaining of living vertebrate motor nerve terminals. J Neurosci 12 : 363-376.

Betz WJ, Ridge RMAP, Bewick G (1993) Comparison of FM1-43 staining patterns and electrophysiological measures of transmitter release at the frog neuromuscular junction. J Physiol (Paris) 87:193202

Bixby JL (1981) Ultrastructural obscrvations on synapse climination in neonatal rabbit skeletal muscle. J Neurocytol 10:81-100.

Brown MC, Holland RL (1979) A central role for denervated tissues in causing nerve sprouting. Nature 282:724-726.

Brown MC, Ironton R (1978) Sprouting and regression of neuromuscular synapses in partially denervated mammalian muscles. J Physiol (Lond) 278:325-348.

Brown MC, Jansen JKS, Van Esssen DC (1976) Polyneuronal innervation of skeletal muscle in new-born rats and its elimination during maturation. J Physiol (Lond) 261:387-422.

Brown MC, Holland RL, Hopkins WG (1981) Motor nerve sprouting. Annu Rev Neurosci 4:17-21.

Brown MC, Hopkins WG, Keynes RJ (1982) Short- and long-term effects of paralysis on the motor innervation of two different neonatal mouse muscles. J Physiol (Lond) 329:439-450.

Callaway E, Soha J, Van Essen DC (1989) Differential loss of neuromuscular connections according to activity level and spinal position of neonatal rabbit soleus motor neurons. J Neurosci 9:1806-1824.

Connor EA, Smith MA (1994) Retrograde signalling in the formation and maintenance of the neuromuscular-junction. J Neurobiol 25:722739.

Covault J, Sanes JR (1986) Distribution of N-CAM in synaptic and extrasynaptic portions of developing and adult skeletal muscle. J Cell Biol 102:716-730.

Dan Y, Poo MM (1992) Hebbian depression of isolated neuromuscular synapses in vitro. Science $256: 1570-1573$.

Dutton EK, Simon AM, Burden SJ (1993) Electrical activity-dependent regulation of the acetylcholine receptor delta subunit gene myoD and myogenin in primary myotubes. Proc Natl Acad Sci USA 90:20402044.

Duxson MJ (1982) The effect of post-synaptic nerve block on development of the neuromuscular junction in postnatal rats. J Neurocytol 11:395-408.

Funakoshi H, Frisen J, Barbany G, Timmusk T, Zachrisson O, Verge VMK, Persson H (1993) Differential expression of messenger-RNA's for neurotrophins and their receptors after axotomy of the sciatic nerve.J Cell Biol 123:455-465.

Gates HJ, Ridge RMAP (1992) The importance of competition between motoneurones in developing rat muscle: effects of partial denervation at birth. J Physiol (Lond) 445:457-472.

Guth L (1962) Neuromuscular function after regeneration of interrupted nerve fibers into partially denervated muscle. Exp Neurol 6:129 141.

Gutmann E, Gutmann L (1944) The effect of galvanic exercise on denervated and reinnervated muscles in the rabbit. J Neurol Neurosurg Psychiatry 7:7--17.

Harish OE, Poo MM (1992) Retrograde modulation at developing neuromuscular synapses: involvement of G-protein and arichidonic acid cascade. Neuron 9:1201-1209.

Harris JB, Ribchester RR (1979) The relationship between end-plate size and transmitter release at normal and dystrophic muscles of the mouse. J Physiol (Lond) 296:245-265.

Heathcote RD (1989) Acetylcholine-gated and chloride conductance channel expression in rat muscle membrane. J Physiol (Lond) 414 473-497.

Hesse S, Lucke D, Malezic M, Bertelt C, Friedrich H (1994) Botulinum toxin treatment for lower-limb extensor spasticity in chronic hemiparetic patients J Neurol Neurosurg Psychiatry 57:1321-1324.

Hines II, Melville E, Wehrmacher W (1945) The effect of electrical stimulation on neuromuscular regeneration. Am J Physiol 144:278 283.

Jones SP, Ridge RMAP (1987) Motor units in a skeletal-muscle of neonatal rat-mechanical properties and weak neuromuscular transmission. J Physiol (Lond) 386:355-375.

Jordan CL, Letinsky MS, Arnold AP (1990) Critical period for the androgenic block of neuromuscular synapse elimination. J Neurobiol 21:760-767

Kowalchuk N, McComas A (1987) Effects of impulse blockade on the contractile properties of rat skeletal muscle. J Physiol (Lond) 382: 255-266.

Kuffler D, Thompson W, Jansen JKS (1977) The elimination of synapses in multiply-innervated skeletal muscle fibers of the rat: dependence of distance between end-plates. Brain Res 138:353-358.

Lindgren CA, Laird MV (1994) Nitroprusside inhibits neurotransmitter release at the frog neuromuscular junction. Neuroreport 5:2205-2208.

Lo YJ, Poo MM (1991) Activity-dependent synaptic competition in vitro: heterosynaptic suppression of developing synapses. Science 254:1019-1022.

Lohof AM, Ip NY, Poo MM (1993) Potentiation of developing synapses by the neurotrophins NT-3 and BDNF. Nature 363:350-353.

Lubischer JL, Jordan CL, Arnold AP (1992) Transient and permanent effects of androgen during synapse elimination in the levator ani muscle of the rat. J Neurobiol 23:1-9.

Lupa MT, Krzemien DM, Schaller KL, Caldwell JH (1995) Expression and distribution of sodium channels in short- and long-term denervated rodent skeletal muscle. J Physiol (Lond) 483:109-118.

Maltin CA, Delday MI, Campbell GP, Hesketh JE (1993) Clenbuterol mimics effects of innervation on myogenic regulatory factor expression. Am J Physiol 265:E176-E178.

Martin AR (1995) Amplification of neuromuscular-transmission by postjunctional folds. Proc R Soc Lond [Biol] 258:321-326.

McArdle JJ (1975) Complex end-plate potentials at the regenerating neuromuscular junction of the rat. Exp Neurol 49:629-638.

Merlie JP, Mudd J, Cheng TC, Olsen EN (1994) Myogenin and acetylcholine receptor alpha gene promoters mediate transcriptional regulation in response to motor innervation. J Biol Chem 269:24612467.

Mokrusch T, Engelhardt A, Eichhorn KF, Prischenk G, Prischenk H, Sack G, Neundorfer B (1990) Effects of long-impulse electrical stimulation on atrophy and fiber type composition of chronically denervated fast rabbit muscle. J Neurol 237:29-34

Nelson PG, Fields RD, Yu C, Liu Y (1993) Synapse elimination from the mouse neuromuscular junction in vitro; a non-Hebbian activitydependent process. J Neurobiol 24:1517-1530.

Nix WA, Hopf HC (1983) Electrical stimulation of regenerating nerve and its effect on motor recovery. Brain Res 272:21-25.

O'Brien RAD, Östberg A, Vrbová G (1978) Observations on the elimination of polyneuronal innervation in developing mammalian skeletal muscle. J Physiol (Lond) 282:571-582 
Purves D (1994) Neural activity and the growth of the brain. Cambridge: Cambridge UP.

Redfern PA (1970) Neuromuscular transmission in new-born rats. J Physiol (Lond) 209:701-709.

Ribchester RR (1988) Activity-dependent and -independent synaptic interactions during reinnervation of partially denervated rat muscle. J Physiol (Lond) 401:53-75.

Ribchester RR (1993) Co-existence and elimination of convergent motor nerve terminals in reinnervated and paralysed adult rat skeletal muscle. J Physiol (Lond) 466:421-441

Ribchester RR, Barry JA(1994) Spatial versus consumptive competition at polyneuronally innervated neuromuscular junctions. Exp Physiol 79:465 494.

Ribchester RR, Taxt T (1983) Motor unit size and synaptic competition in rat lumbrical muscles reinnervated by active and inactive motor axons. J Physiol (Lond) 344:89-111.

Ribchester RR, Taxt T (1984) Repression of inactive motor nerve terminals in partially denervated rat muscle after regeneration of active motor axons. J Physiol (Lond) 347:497-511.

Ribchester RR, Mao F, Betz WJ (1994) Optical measurements of activity-dependent membrane recycling in motor-nerve terminals of mammalian skeletal-muscle Proc R Soc Lond [Biol] 255:61-66.

Rich MM, Lichtman JW (1989) In vivo visualization of presynaptic and postsynaptic changes during synapse elimination in reinnervated mouse muscle. J Neurosci 9:1781-1805.

Ridge RMAP, Betz WJ (1984) The effect of selective chronic stimulation on motor unit size in developing rat muscle. J Neurosci 4:2614-2620.
Slater CR, Lyons PR, Walls TJ, Fawcett PRW, Young C (1992) Structure and function of neuromuscular-junctions in the vastus-lateralis of man-a motor point biopsy study of two groups of patients. Brain 115:451-478.

Son YJ, Thompson WJ (1995a) Nerve sprouting in muscle is induced and guided by processes extended by Schwann cells. Neuron 14:133141.

Son YJ, Thompson WJ (1995b) Schwann-cell processes guide regeneration of peripheral axons. Neuron 14:125-132.

Taxt T (1983) Local and systemic effects of tetrodotoxin on the formation and elimination of synapses in reinnervated adult rat muscle. J Physiol (Lond) 340:175-194.

Thompson WJ (1978) Reinnervation of partially denervated rat muscle. Acta Physiol Scand 103:81-91.

Thompson WJ, Kuffler DP, Jansen JKS (1979) The effect of prolonged reversible block of nerve impulses on the elimination of polyneuronal innervation of new-born rat skeletal muscle fibers. Neuroscience $4: 271-281$.

Wang T, Xie Z, Lu B (1995) Nitric ocxide mediates activity-dependent synaptic suppression at developing neuromuscular synapses. Nature 374:262-266.

Werle MJ, Herrera AA (1991) Elevated levels of polyneuronal innervation persist for as long as two years in reinnervated frog neuromuscular-junctions. J Neurobiol 22:97-103.

Wilkinson RS, Lunin SD, Stevermer JJ (1992) regulation of single quantal efficacy at the snake neuromuscular-junction. J Physiol (Lond) 448:413-436. 